\title{
Automating Secondary School Libraries: A Web-Based Library Management System
}

\author{
Abrizah Abdullah, Nor Edzan Nasir, Lok Chee Mei and Khoo Mei Lee \\ MLIS Program \\ Faculty of Computer Science \& Information Technology, \\ University of Malaya, \\ 50603 Kuala Lumpur \\ Malaysia \\ abrizah@fsktm.um.edu.my,edzan@fsktm.um.edu.my
}

\begin{abstract}
This paper describes the development of a web-based school library management system for secondary schools in Malaysia (WBSSLMS), which aims to provide an effective and efficient way of acquiring, cataloguing, searching, retrieving, downloading and maintaining of library materials. The systems operates in a consortium where secondary school libraries can participate as members to share information resources and still maintain separate library databases. Information gathered from various literature, onsite visits to school libraries, brainstorming sessions with teacher-librarians and observation on the present systems used, have helped produce ideas in designing and implementing the systems. WBSSLMS consists of seven main modules and each is basically targeted to three types of users; i.e. students, teacher-librarians and systems administrators. Any computer, regardless of its operating system, could access any of the modules as long it had Internet access and a browser. The modules are Registration, Acquisition, Cataloguing, Online Public Access Catalogue (OPAC), Circulation, Maintenance and Information Management.. This paper also presents the strengths and limitations of the systems, and also the possible future enhancements. User acceptance tests showed that a high majority of respondents found the systems easy to use. They also found that the modules are complete and have an appealing interface. It is foreseen that WBSSLMS has met the requirements to meet the needs of a library automated systems, as well as a management information systems.
\end{abstract}

\section{Introduction}

Professional literature contains many statements about the value and benefits of school library automation. The reasons given for automating a school library range from the practical to the philosophical, and cover aspects such as school library management, school and library efficiency, curriculum support, information access, information skills instruction, public relations, facilitating collaboration, and promoting equity. The research literature reinforces the value of school library automation. While it is not possible in the context of this article to provide a comprehensive overview of the research, some such studies of the work of the teacher librarian, and of students information retrieval activities, suggest that the effects of school library automation are indeed generally positive. 
On-site visits to many school libraries in Malaysia revealed the state of library catalogues in these schools: out-of-date card catalogues, unfiled catalogue cards, and cataloguing of questionable quality. At present, school library systems in Malaysia are mostly stand-alone, turnkey products based on the personal computer. Library functions are often not integrated. School libraries in developed countries on the other hand are reaping the benefits of recent developments in the computer and library automation industries with the development of PC-based client/server. Most systems are moving from PC-based to the webbased library system as a result of the widespread use of the Internet and the World Wide Web. Powerful but relatively inexpensive servers make it possible for school libraries in Malaysia to have the same systems as larger libraries or consortiums. With the advent of information technology and communication, and in the light of the Smart School concept, there is a need for school libraries in Malaysia to meet a certain qualifying condition in order to provide better services to the users. The conventional way of having to achieve information in physical condition (e.g. having to search in the library itself) no longer applied to the modern society. With the national vision to achieve a developed country status by the year 2020 , school libraries too have to enhance themselves by providing an easier, faster, safer and convenient access to the users.

The objective of this paper is to describe the development of a web-based school library management systems for secondary schools in Malaysia (WBSSLMS), which aims to provide an effective and efficient way of access to the library utilities and ease of use among authorized users. The systems operates in a school library consortium where secondary school libraries can participate as members of WBSSLMS to share information resources and still maintain separate library databases. Succinctly stated, a consortium means having at least two libraries, linked via a telecommunication network, using the same hardware platform and library application software, and often includes the sharing of data files. This leads and encourages collaboration and resource sharing among participating members to ensure that students receive excellent and up-to-date library services and have access to the world of information.

\section{Objectives of the Web-Based System}

WBSSLMS is developed with the overall objective to provide an effective and efficient way of acquiring, cataloguing, searching, retrieving, downloading and maintaining of library materials. The system is developed with the following specific objectives:

a) To establish a consistent and user-friendly graphical user interface for the ease of use to target users

b) To establish a secure login system limited to only authorized users.

c) To enable easy and fast information retrieval from the library database through online searching.

d) To allow for different types of searching strategies for different types of users.

e) To provide a search function for the teacher-librarians to verify the existence of an item in the library before acquiring the item.

f) To provide better maintenance of the library's database for teacher librarians to add, update or delete data.

g) To establish a sharing environment among members of the school library consortium.

h) To enable downloading of information from one database to another.

i) To establish an easy and understandable help system to guide users how to perform a specific library function online.

j) To enable access to the system 24 hours daily. 
With the specific objectives in mind, the functional requirements of the system are determined and further described in the following section under analysis of the systems requirement.

\section{The Framework For WBSSLMS}

The development for WBSSLMS follows along the five phases which is described in full in this section.

1) Problem identification

Information gathered from various literature, on-site visits to school libraries, brainstorming sessions with teacher-librarians and observation on the present systems used in school libraries, have helped produce ideas in designing and implementing the systems. On-site visits to school libraries in Malaysia revealed that the majority of school libraries are still being managed the conventional way. Teacher librarians feel that they are overloaded with a lot of paper work and they have difficulties in fulfilling the needs of users especially with the manual cataloguing and searching systems. Out-of-date card catalogues and unfiled catalogue cards, and cataloguing of questionable quality are the common complaints. Time required to process the library materials is extremely high. Teacher librarians often have to stay back after school or even work on Saturdays in order to meet the milestones of performing the required library tasks. Discussions with students also indicated that they have problems searching for books and often they could not find the books they want. Most of them, when asked, felt that there should be a better, convenient and more advanced way of getting the required information from their school library. Discussion with teacher librarians and observation on the systems used in school libraries also revealed that there has not been much major success of the systems used at present.

2) Analysis of the systems requirements

Based on the analysis of existing library systems and on the objectives of WBSSLMS, the functional and non-functional requirements of the new system are determined. A functional requirement describes an interaction between the system and its environment. It is a statement of services that the system should provide, how the system should react to a particular input and how the system should behave in particular situations (Sommerville, 1995). In other words, the functional requirements of WBSSLMS are the library functions that the system needs to provide in order to fulfill the user's requirements. Figure 1 describes the major functional requirements for the system.

Figure 1: The functional requirements of WBSSLMS

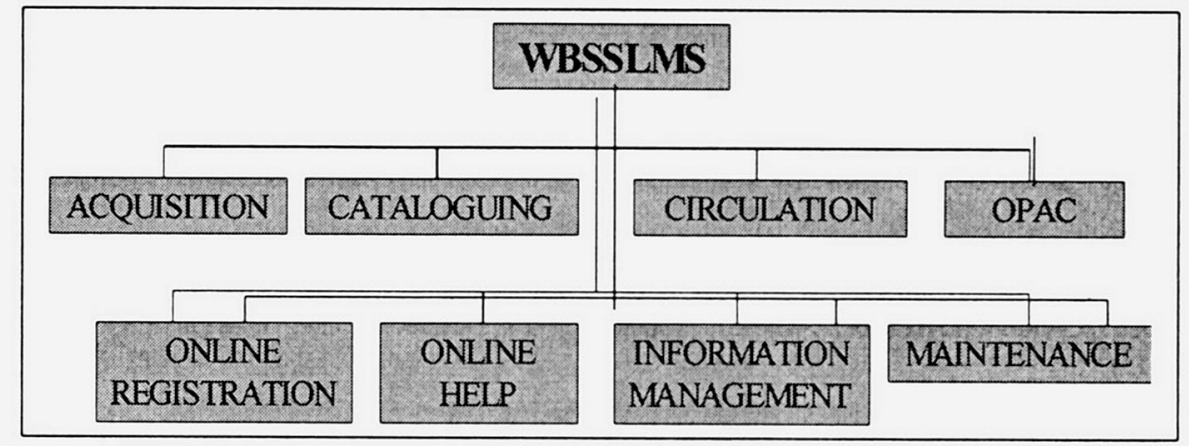


The Acquisition Module is designed specifically to manage library's vendor information and purchase orders. Since this module is fully integrated with the Cataloguing Module, it allows downloading of data from the Acquisition to the Cataloguing Module. This feature avoids duplication of data entry.

Cataloguing module enables searching, downloading, updating records and adding new records into the library database. After conducting a search at any participating libraries, teacher librarians can select bibliographic records and download them directly to their database without having to key-in the information themselves. This speeds the availability of items to the library users. It also eliminates cataloguing of questionable quality.

Check, renewals, reserve and patron information are all included in the cornucopia of options for the circulation module made available to the joining school libraries. Users are allowed to renew the borrowed item and reserve any particular items in the library holdings from home. The systems used in school libraries at present lack this function.

The web OPAC enables users to search the school library catalog from home either by using simple or advanced search. It also enables users to perform a particular search on all libraries that join in the consortium. Users may perform basic searches i.e. search the collection by the following fields - title, author, subject or keyword. In advance search, users can specify that the document records must contain all of the words that have been entered, any of the words that users entered, or the exact phrase that users entered, for any of the fields.

Online Registration Module registers new users - 24 hours daily. Schools, students, teachers and teacher librarian may sign in as members under this module. To keep track of the users records and for security reasons, new users must register themselves when they are first introduced to use the system. This module also allows login into the database and the system. Only authorized users are allowed access into the system.

Online Help provides information to users on how to use the system as well as assists users in performing a particular library function in any of the modules. Information Management Module contains FAQs and information about the participating schools. GUIinterface report utilities in this module increase opportunities for school libraries to customize both their overdue notices and their statistical reports.

Maintenance serves as the back-end system where only authorized users will have access to this module. This module maintains user and item records. Administrators are able to add new users and items, modify information in the database and also delete obsolete records.

A non-functional requirement describes a restriction on the system's performance that limits the choices for constructing a solution to the problem (Pfleeger, 1998). The followings are the constraints under which the system must operate and the standards which must be met by the system.:

a) User-friendliness - the system has a user-friendly interface in order to ease the users' usage of the system and to reduce the learning curves of the users.

b) Speed - The response time is within a reasonable interval time. Users will not be kept waiting for a long time for the search results. 
c) Reliability - The system is reliable in performing its functions and will not cause unnecessary downtime of the accessed environment.

d) Flexibility - The system has the flexibility to be changed to meet various user requirements

e) Robustness - The system is robust enough to handle an anticipated or unanticipated error.

f) Correctness - The system satisfies the specifications and fulfills the needs and objectives of a secondary school library.

g) Modularity - The system is broken down into modules of functions to facilitate maintenance and future enhancements.

h) Security - Security measures are implemented to prohibit unauthorized access to the administrators and teacher librarians modules.

3) System design

In WBSSLMS, the system design process ensures that the system developed meets the requirements effectively and efficiently, as well as satisfies the needs of the users. The system is divided into three entities, namely user, teacher-librarian and administrator. Each of these entities performs different system functions. The entities are structured to the connectivity with the modules or library functions.

User is the name used to represent the students, teachers, teacher-librarians and system administrators. They are the users of the system, and they will perform functions such as new user registration and login to the system, online searching, online renewal and reservation of books, and online help. The teacher-librarians have more functions to perform under the teacher-librarian entity - cataloguing. acquisition, circulation (loan and return) and fines. The administrator is responsible for the database maintenance and this include functions such as adding, modifying and deleting files in the database, as well as in the information module. Figure 2, 3, and 4 describes the structured chart of three entities with the respective modules.

Figure 2: Structured Chart for WBSSLMS's User Entity

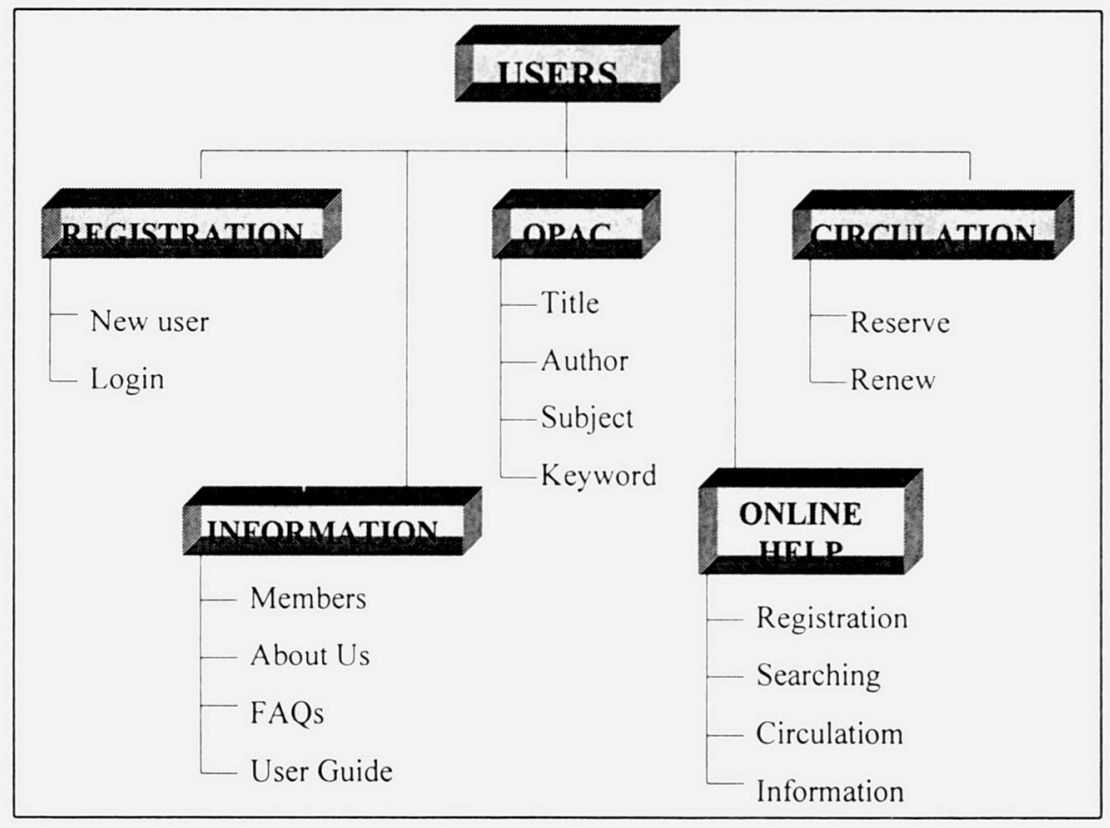


Figure 3: Structured Chart for WBSSLMS's Teacher-Librarian Entity
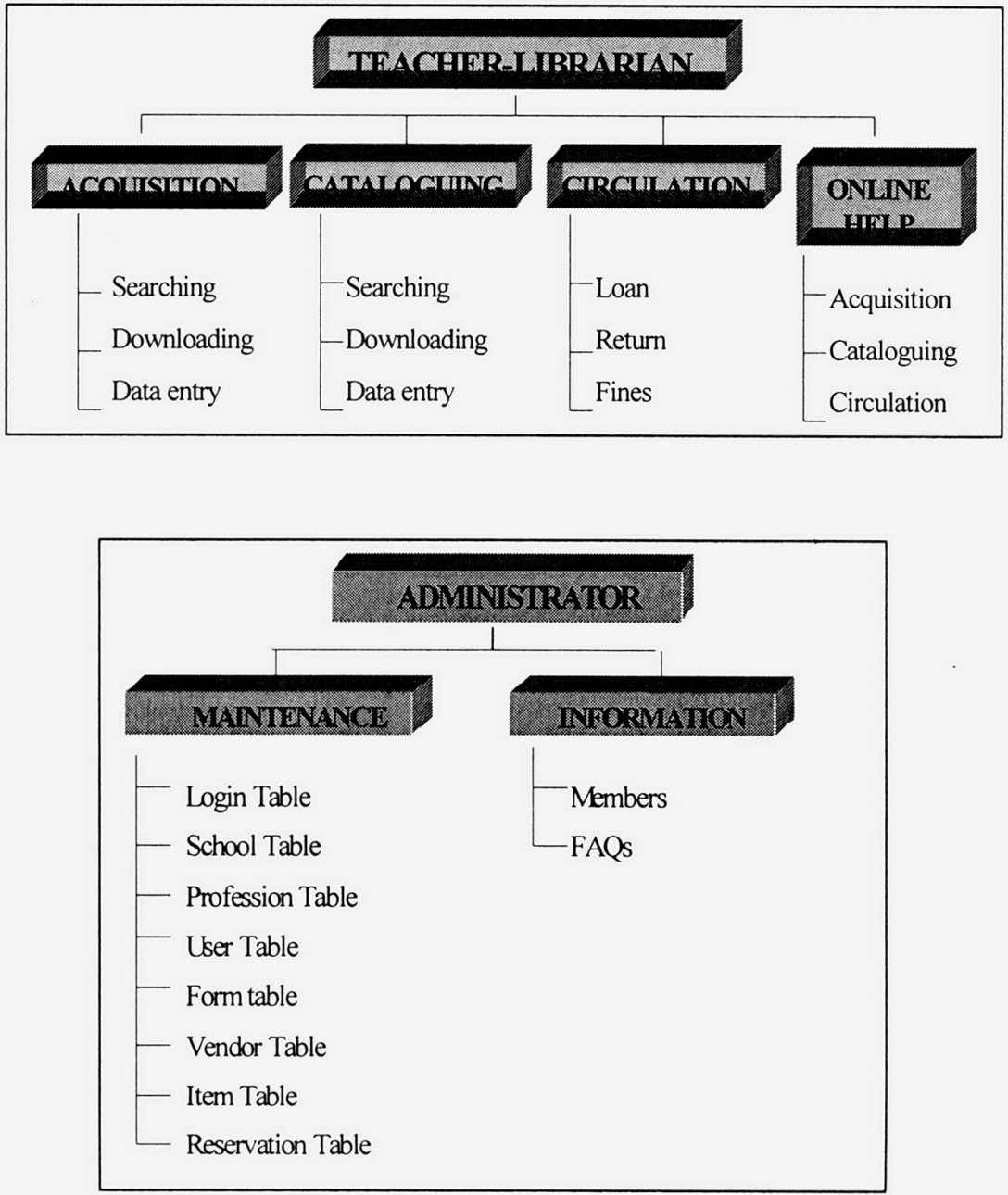

4) System implementation

System implementation is the construction of the application and the transformation of the design into a feasible and workable product. It is a stage of developing WBSSLMS based on the specified requirements. The system is developed using the following tools:

a) Microsoft Windows 2000 for the operating system

b) Microsoft SQL Server 7 for the database

c) Microsoft Visual InterDev 6.0 as the web application tool

d) Internet Information Server for the web server

e) Internet Explorer 5.0

The most prominent characteristic of online catalogs is their ease of use. User-friendly and appealing interfaces will motivate students to interact with the system and to browse through and play with information in a way that naturally tends to improve their information skills. Each function in WBSSLMS is arranged systematically on the left side of each Web page, as well as at the menu on the administrator's page to give the web site a structured appearance. Colors used are carefully coordinated, graphics and images are used where possible in order to liven up the pages. Animated graphics are minimized so as to give the web site a clean, professional look, as well as to reduce the time needed to load the web pages. Figures 5, 6 and 7 presents WBSSLMS's Main Page, interface for both teacherlibrarians and administrator, and interface for normal users. 
Figure 5: WBSSLMS's Main Page

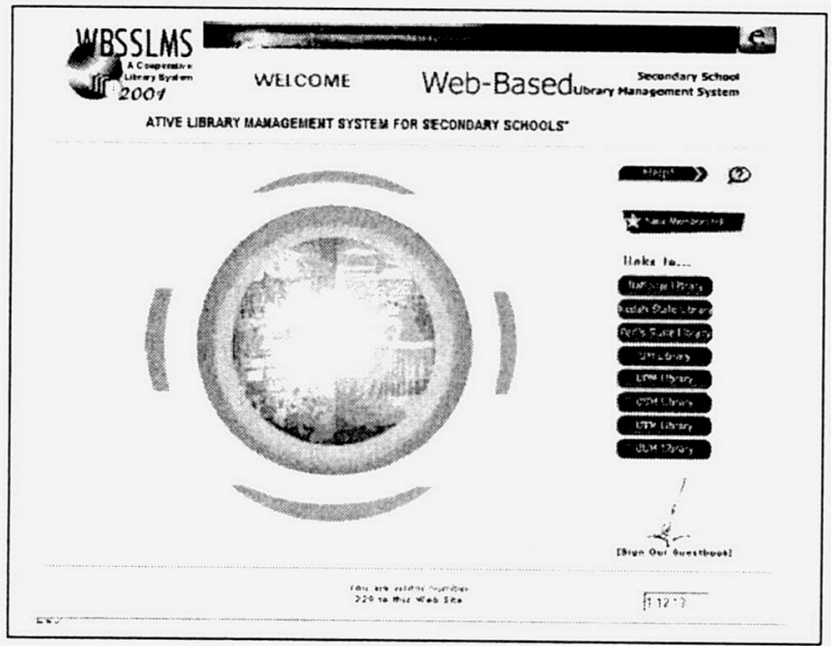

Figure 6: Interface for teacher-librarians and administrator

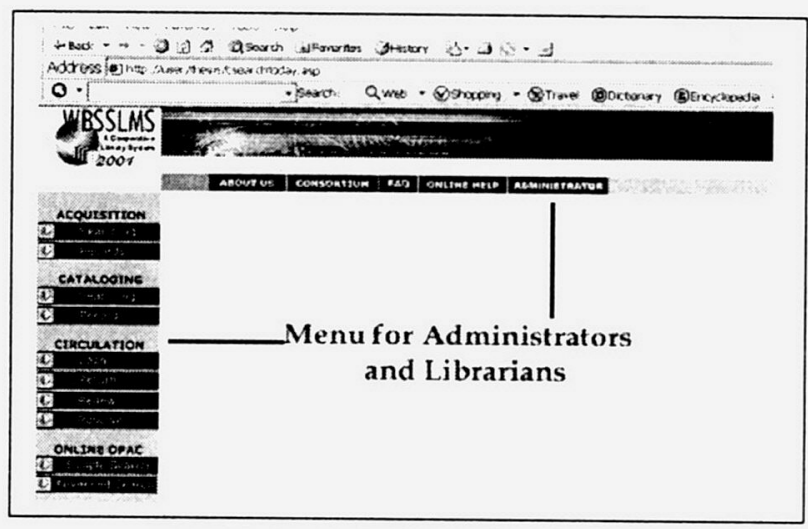

Figure 7: Interface for normal users

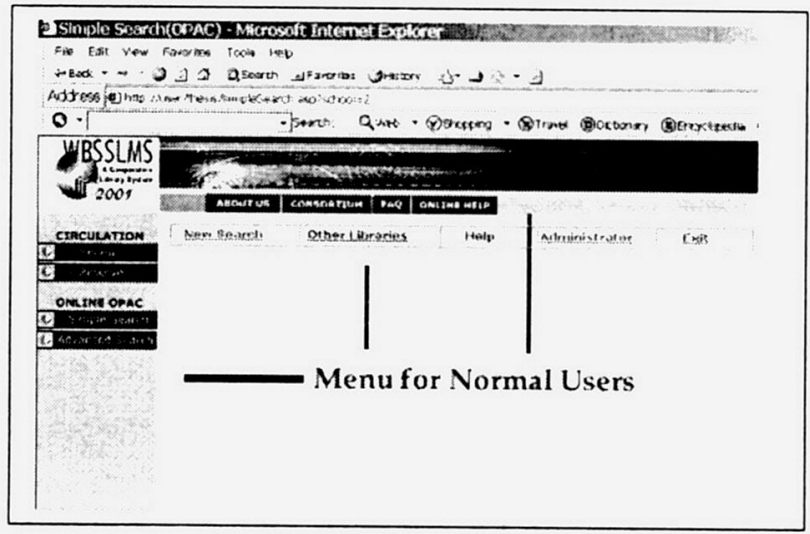

5) System testing

A large system like WBSSLMS involves several types of testing. Unit testing, module testing, integration testing and system testing were conducted to ensure that the system is developed according to its specification, and every function implemented in the system worked correctly as expected. In addition, several computers were used to access the 
system simultaneously in order to test the scalability of the system. It was found that the system runs smoothly without much complication and has achieved the scalability requirement. The system has the following strengths:

a) WBSSLMS is packed with functions that are practical and easily understood. The functions are kept as simple as possible in order to minimize user's action and at the same time minimizing errors.

b) The system was developed on the Windows platform, the most popular and widely used operating system. Incompatibility issues are least likely to arise, as it is easily deployed into any machine running on the Windows platform.

c) The user interface is very simple and easy to use. The learning curve is foreseen to be short and users should be able to use the system with ease within minutes.

d) One of the plus points of WBSSLMS is its ability to download bibliographic records and share information among the consortium members. This will greatly reduce the time and energy spent on entering and searching of information.

e) The Web OPAC provides several search criteria suitable for both novice and expert users to search the library's catalogue.

f) The system provides features where the teacher librarians do not need to know about the system structure, where the database resides, its database management system or anything related to the system built. They will only need to know how to use the system and this is facilitated by the Online Help.

g) Users can access this system from home and anywhere in the world, as long as they are connected to the Internet.

h) This system serves as a management information system as well. It has the capability of generating reports, statistics and graphs upon request.

i) The system is secured enough since user ID and password are required to access the administrator and teacher librarian modules.

The major limitation of WBSSLMS is that the number of consortium members at present is fixed to only four schools due to database allocation and disk space constraints. However the system can be extended in the future to allow more school libraries to join in the consortium. It may be enhanced to include as many libraries in order to provide a platform for more schools to share their resources. This may allow school libraries to fully utilize the downloading function as their resources are no longer limited to only four schools.

\section{User Acceptance Test}

To determine if the system can be accepted for operational use, a dummy database consisting of a total of 50 records were tested by 10 volunteers comprising 7 students and 3 teacher librarians. The user acceptance questionnaire consists of 10 and 28 questions for the students and teacher-librarians respectively. Questionnaire for students requires them to rate the user interface in terms of its user friendliness, language used, color and screen design, and seek their opinions on the renew, reserve and search functions. Questionnaires for administrators (teacher librarians) require them to rate the various modules provided in the systems and give comments in the space provided.

In general, all students found the system easy to use and they indicated they understand the language used for the system (English). None of them gave a negative rating to the systems. They commented that the WBSSLMS interface is appealing and attractive and is suitable for secondary school usage. Six students indicated that the functions renew, 
reserve, simple search and advance search are 'absolutely easy to use' and rated the functions user ID retrieval and guest book as 'excellent'.

Responses from the teacher librarians also show that the system has met its overall requirements and serves well as a consortium of library system. All 3 respondents ranked the following functions 'absolutely easy to use' and 'excellent' - acquisition searchingdownloading. cataloguing searching-downloading, cataloguing-updating records, cataloguing new records, circulation (loan and return), maintenance (check reservation, paying fines, loan and return), user maintenance, item maintenance, report \& statistics management. However two teacher librarians indicated preference for Bahasa Melayu to English as the language of the system as the former is the medium of instruction in Malaysian schools. They also commented that the display of records should be in bibliographic format, rather than labeled format.

\section{Conclusion}

School libraries, however small, are now complex organizations that create and use vast quantities of information. They provide a setting where students can develop the skills they will need as adults in an information rich world - the skills of locating, retrieving, analyzing, evaluating, using and communicating information and ideas (Singh, 1996). Consequently, there is a need to ensure that this information is organized and managed in such a way that school objectives are achieved. Information access limited to school hours and only to one's own school is no longer appropriate in this information age. In relation to this, today's school has, or should have, an information management system that are of particular value to the school community. As web-based library services is a trend; libraries nowadays are taking full advantages of the Internet and web facilities to provide a more efficient service.

WBSSLMS, a fully operational web-based library management system, has successfully achieved and fulfilled the objectives and requirements specifications as a consortium of online library system. Although it has not being used as yet in real situation, it is foreseen that WBSSLMS has met the requirements to meet the needs of a sophisticated library automated system combining access to the school library catalogue and the Internet for Malaysian students and teachers especially in the light of the Smart School concept.

\section{REFERENCES}

Pfleeger, Shari Lawrence (1998). Software engineering: theory and practice. Englewood Cliffs, N.J.: Prentice-Hall

Singh. Diljit (1996). School libraries as catalysts of change. Libraries in National Development $\mathrm{Vol}$ 1: Papers and proceedings of the Tenth Congress of Southeast Asian Libraries CONSAL-X. Kuala Lumpur. Malaysia, May 21-25.

Sommerville, Ian (1995). Soffware engineering. $5^{\text {th }}$.ed. London: Addison-Wesley. 